Revista Brasileira de Agricultura Irrigada v.9, nº.3, p. 136 - 144, 2015

ISSN 1982-7679 (On-line)

Fortaleza, CE, INOVAGRI - http://www.inovagri.org.br

DOI: $10.7127 /$ rbai.v9n300299

Protocolo 299.15 - 30/03/2015 Aprovado em 10/05/2015

\title{
PRODUÇÃO DE MELANCIA E TEORES DE SÓLIDOS SOLÚVEIS TOTAIS EM RESPOSTA A ADUBAÇÃO NITROGENADA E POTÁSSICA
}

Vicente Filho Alves Silva ${ }^{1}$, Nilvan Carvalho Melo ${ }^{2}$, Jessivaldo Rodrigues Galvão ${ }^{3}$, Deivison Rodrigues da Silva ${ }^{4}$, Wendel Valter da Silveira Pereira ${ }^{4}$, Flávio Henrique Santos Rodrigues ${ }^{4}$.

\section{RESUMO}

A melancia é uma das principais espécies olerícolas cultivadas no Brasil, destacando-se a região Nordeste, que apresenta condições de solo e clima favoráveis ao seu cultivo, podendo ser cultivada o ano inteiro sob condições irrigadas. $O$ trabalho objetivou avaliar os componentes de produção e os teores de sólidos solúveis totais de frutos de melancia em relação às doses de nitrogênio e potássio. Foi adotado o delineamento experimental em blocos ao acaso distribuídos em esquema fatorial 4 x 4 e seis repetições. Os fatores foram: 4 doses de $\mathrm{N}\left(0 ; 50 ; 100\right.$ e $\left.150 \mathrm{~kg} \mathrm{ha}^{-1}\right)$ na forma de ureia e 4 de $\mathrm{K}_{2} \mathrm{O}\left(0 ; 100 ; 150\right.$ e $\left.200 \mathrm{~kg} \mathrm{ha}^{-1}\right)$ na forma de cloreto de potássio. Avaliou-se a massa, diâmetro e número de frutos, sólidos solúveis totais, produção por planta e produtividade. A maior produtividade obtida foi de $87,86 \mathrm{t} \mathrm{ha}^{-1}$ com $66,0 \mathrm{~kg}$ de $\mathrm{N} \mathrm{ha}^{-1}$. Para massa, diâmetro dos frutos e sólidos solúveis totais, as doses de $\mathrm{N}$ consideradas máximas foram, respectivamente, 99,$5 ; 65,9$ e $50,0 \mathrm{~kg} \mathrm{ha}^{-1}$. Não foram verificados efeitos dos tratamentos sobre o número de frutos. O potássio não influenciou as variáveis.

Palavras-chave: Citrullus lanatus, crimson sweet, produtividade.

\section{PRODUCTION OF WATERMELON AND TOTAL SOLUBLE SOLIDS IN RESPONSE TO NITROGEN AND POTASSIUM FERTILIZATION}

\footnotetext{
ABSTRACT

The watermelon is one of the major vegetable crops grown in Brazil, especially in the Northeast, which has soil and climate conditions favorable to its cultivation, and can be cultivated all year about irrigated conditions. The study aimed to evaluate the production of components and the total soluble solids content of watermelon fruits in relation to the nitrogen and potassium. The experimental design was adopted in blocks distributed in a factorial $4 \times 4$ with 06 repetitions. The factors were: 4 doses of $N\left(0,50,100\right.$ and $\left.150 \mathrm{~kg} \mathrm{ha}^{-1}\right)$ in the form of urea and 4 doses of $\mathrm{K} 2 \mathrm{O}\left(0,100,150\right.$ and $\left.200 \mathrm{~kg} \mathrm{ha}^{-1}\right)$ in the form of potassium chloride. It

${ }^{1}$ Prof. Dr., Universidade Federal Rural da Amazônia

${ }^{2}$ MSc., Doutorando pela Universidade Estadual Paulista "Júlio de Mesquita Filho"/Jaboticabal-SP.

${ }^{3}$ Eng. Agrônomo, Dr. em Ciências Agrárias da Universidade Federal Rural da Amazônia.

${ }^{4}$ Estudantes de graduação da Universidade Federal Rural da Amazônia.
} 
was evaluated the mass, diameter, number of fruits, total soluble solids, yield per plant and productivity. The highest yield obtained was $87,86 \mathrm{t} \mathrm{ha}^{-1}$ with $66,0 \mathrm{~kg} \mathrm{~N}$ ha ${ }^{-1}$. For mass, diameter of fruits and total soluble solids, the $\mathrm{N}$ doses considered maximum were, respectively, 99,5; 65,9 and 50,0 $\mathrm{kg} \mathrm{ha}^{-1}$. No effects were observed on the treatments about the number of fruits. Potassium didn't influence the variables.

Keywords: Citrullus lanatus, crimson sweet, productivity.

\section{INTRODUÇÃO}

A melancia [Citrullus lanatus (Thunb) Mansf.] é uma das principais espécies olerícolas cultivadas no Brasil, em especial na região Nordeste, que apresenta condições de solo e clima favoráveis ao seu cultivo, podendo ser cultivada o ano inteiro sob condições irrigadas.

A adubação é uma prática com potencial reconhecido na olericultura. $\mathrm{O}$ emprego dessa prática agrícola permite, no período correto, melhor adequação da quantidade e época do fornecimento de nutrientes para a planta, além de maior eficiência da fertilização. Embora a melancia possa tolerar pequenos veranicos, paralisando o seu crescimento, a falta de umidade no solo durante as fases de floração e frutificação, diminui a produtividade em decorrência da baixa frutificação e à redução do tamanho dos frutos.

Com boa situação hídrica, baixa umidade relativa do ar, temperatura elevada e luminosidade alta, têm-se condições climáticas ideais para uma boa produtividade da cultura e obtenção de frutos de ótima qualidade, pois aumentam o conteúdo de açúcares e melhoram o aroma, o sabor e a consistência dos frutos (SILVA, 2010). Embora cultivada em variados tipos de solos, os de textura areno-argilosa, profundos e bem estruturados são os mais apropriados. Vale ressaltar que a melancia é levemente tolerante à acidez do solo, se desenvolvendo bem em $\mathrm{pH}\left(\mathrm{H}_{2} \mathrm{O}\right)$ de 5,0 a 6,8 (FELTRIM, 2010).

A cultura da melancia tem a nutrição mineral como um dos fatores que afeta diretamente a produtividade e qualidade dos frutos. O nitrogênio e o potássio são considerados os nutrientes mais exigidos pela cultura (GRANGEIRO;
CECÍLIO FILHO, 2004), onde se tem que o nitrogênio é o elemento com maior participação na produção e o potássio apresenta maior efetividade na qualidade frutífera (FELTRIM, 2010).

$\mathrm{O}$ nitrogênio $(\mathrm{N})$ é um dos mais importantes, pois influencia a qualidade fotossintética e o desenvolvimento da planta (DORDAS; SIOULAS, 2008). Assim, a deficiência desse nutriente, em fase inicial, afeta o desenvolvimento da planta, diminuindo o rendimento final das culturas (ZHANG et al., 2012).

Por outro lado, dosagens elevadas de $\mathrm{N}$ promovem um excessivo desenvolvimento vegetativo, além de atraso na maturidade. Dessa forma, considera-se que a nutrição nitrogenada é uma das facetas mais cruciais da produção de melancia. Nos últimos tempos, com o aumento dos custos de fertilizante e o foco crescente sobre as emissões de gases de efeito estufa, uma maior atenção foi direcionada para o uso eficiente de fertilizantes nitrogenados (ROCHESTER et al., 2007; DONG et al., 2012).

O potássio $(\mathrm{K})$ é um nutriente essencial para o crescimento e desenvolvimento das plantas, pois desempenha papel vital nas células vegetais, incluindo osmorregulação, fotossíntese, ativação enzimática e a formação de proteínas (KUMAR et al., 2007).

A deficiência de $\mathrm{K}$ é um problema generalizado em alguns solos, o que resulta na redução do crescimento da planta, teor de açúcar da fruta, vitamina $\mathrm{C}$ e espessura da casca, sendo a aplicação correta de adubação potássica a maneira mais eficaz de repor a deficiência do elemento (WANG et al., 2010; HUANG, et al., 2013). Entretanto, a demanda por fertilizantes 
potássicos excedeu a capacidade produtiva (LIU, 2012). Uma maior eficiência do K nas plantas e a determinação de doses adequadas são formas atraentes para redução no custo da produção agrícola (RENGEL; DAMON, 2008).

O manejo adequado da nutrição mineral pode aperfeiçoar o sistema de produção da cultura da melancia, além da melhoria da qualidade dos frutos e da ampliação do uso de fertilizantes pelas plantas podendo, assim, refletir em maior taxa de retorno econômico para a atividade. Diante destes fatores, o estudo objetivou avaliar a influência da adubação nitrogenada e potássica sobre os componentes de produção e os teores de sólidos solúveis totais de frutos de melancia.

\section{MATERIAL E MÉTODOS}

$\mathrm{O}$ experimento foi conduzido em área experimental do Instituto de Ciências Agrárias (ICA) da Universidade Federal Rural da Amazônia (UFRA) no município de Belém/PA, no período de agosto a novembro de 2011, localizada nas coordenadas geodésicas $01^{\circ} 27^{\prime} 9.35^{\prime \prime} \mathrm{S}$ latitude e $48^{\circ} 26^{\prime} 30.52^{\prime \prime} \mathrm{W}$ longitude, com altitude média de $13 \mathrm{~m}$. De acordo com classificação de Köppen, o clima predominante na região é o Afi com temperatura média anual de $26^{\circ} \mathrm{C}$, com alta pluviosidade, sendo a média de $2.754,4 \mathrm{~mm}$ anuais, ocorrendo uma estação chuvosa de dezembro a maio e uma menos chuvosa, de junho a novembro. Na figura 2 são observados os dados climatológicos do ano de 2011.

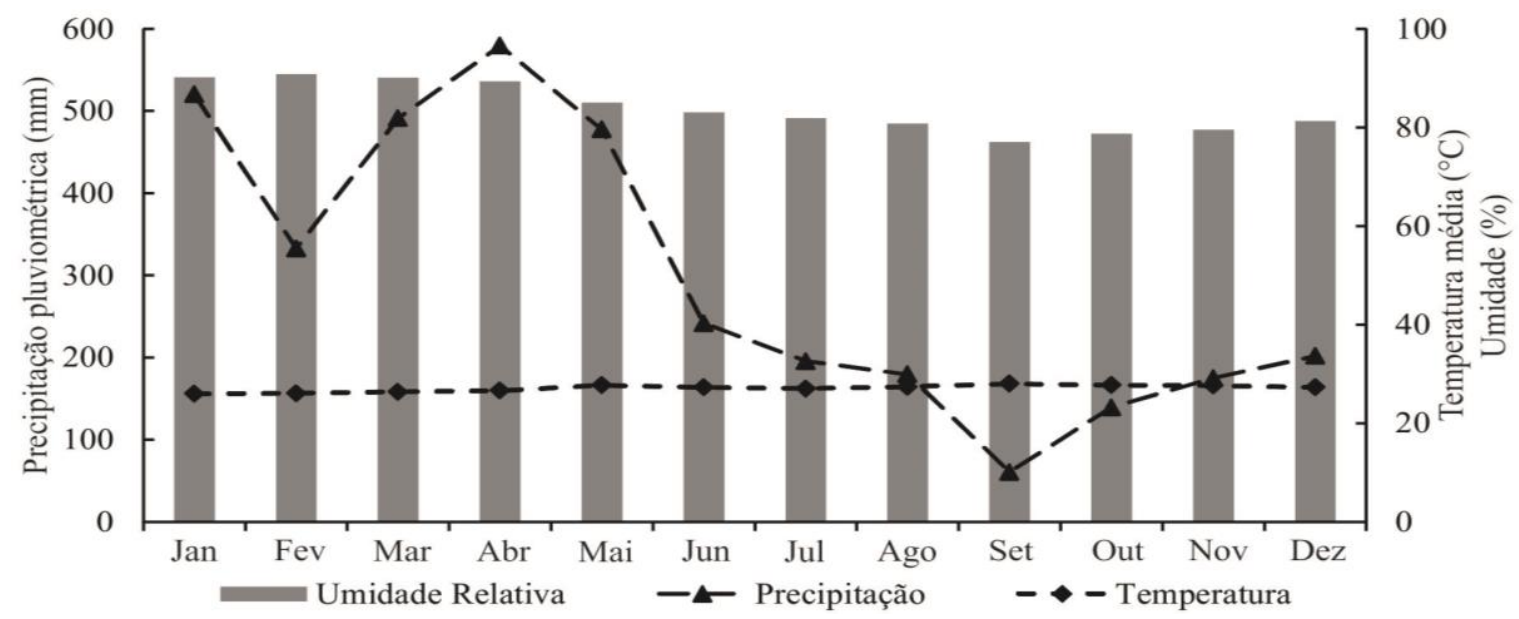

Figura 1. Dados climáticos de Belém/PA, no ano de 2011 (INMET).

O solo da área experimental é classificado como Latossolo Amarelo distrófico de textura média (EMBRAPA, 2006). Para a caracterização da fertilidade do solo, foram coletadas amostras de solo da área experimental, compostas na profundidade de 0,0 a $0,2 \mathrm{~m}$. O solo pode ser considerado de fertilidade média com altos teores de $\mathrm{P}$, baixos teores de $\mathrm{K}$ e $\mathrm{Ca}$, médios teores de $\mathrm{Mg}$ e teores medianamente elevados de Al (CRAVO et al., 2007). Os resultados das análises químicas encontram-se na Tabela 1.

Tabela 1. Atributos químicos do solo, na camada de 0,0 - 0,2 $\mathrm{m}$ de profundidade, antes da instalação do experimento.

\begin{tabular}{cccccccccccc}
\hline $\mathrm{pH}$ & $\mathrm{MO}$ & $\mathrm{P}$ & $\mathrm{K}^{+}$ & $\mathrm{Ca}^{++}$ & $\mathrm{Mg}^{++}$ & $\mathrm{Al}^{+++}$ & $\mathrm{H}+\mathrm{Al}$ & $\mathrm{SB}$ & $\mathrm{T}$ & $\mathrm{V}$ & $\mathrm{m}$ \\
\hline $\mathrm{H}_{2} \mathrm{O} \mathrm{KCl}$ & $\mathrm{g} \mathrm{dm}^{-3}$ & $\mathrm{mg} \mathrm{dm}$ & & \multicolumn{7}{c}{$\mathrm{cmol}_{\mathrm{c}} \mathrm{dm}^{-3}$} \\
$5,1 \quad 4,0$ & 18,56 & 54,69 & 0,18 & 1,32 & 1,09 & 0,68 & 5,05 & 2,48 & 7,53 & 32,9 & 21,52 \\
\hline
\end{tabular}


Utilizou-se o delineamento experimental em blocos ao acaso, em esquema fatorial $4 \times 4$, com seis repetições, perfazendo um total de 96 parcelas experimentais. Os tratamentos foram quatro doses de nitrogênio $(0 ; 50 ; 100$ e $150 \mathrm{~kg}$ $\left.\mathrm{ha}^{-1}\right)$, na forma de ureia e quatro de $\mathrm{K}_{2} \mathrm{O}(0 ; 100$; 150 e $200 \mathrm{~kg} \mathrm{ha}^{-1}$ ), na forma de cloreto de potássio $(\mathrm{KCl})$ que foram determinadas em função das exigências da cultura e do solo recomendadas para a região, de acordo com as recomendações de Cravo et al., (2007). As parcelas experimentais constaram de $6,0 \times 5,0 \mathrm{~m}$ espaçadas em 1,0 m uma das outras, sendo cada parcela constituída com 18 plantas, com espaçamento de 3,0 m entre linhas e 1,0 m entre plantas. Considerou-se apenas a fileira central como parcela útil (4 plantas), eliminando-se as demais avaliadas como bordadura.

O preparo do solo foi realizado com grade aradora na profundidade de 0,0 a $0,2 \mathrm{~m}$. A calagem foi efetuada em função da análise química do solo, aplicando-se em cobertura e incorporada ao solo, utilizando calcário dolomítico (PRNT 90\%) na quantidade de 1,36 t $\mathrm{ha}^{-1}, 45$ dias antes da semeadura, considerando a saturação por alumínio do solo.

Foi realizada uma adubação fosfatada (50 $\mathrm{kg}$ de $\mathrm{P}_{2} \mathrm{O}_{5}$ ha $^{-1}$ na forma de Superfosfato triplo) realizada em uma única vez na semeadura, incorporada em covas abertas, com dimensões de 0,4 x 0,4 x 0,4 m, juntamente com a adubação orgânica na base de $3 \mathrm{~L}$ de esterco bovino/cova. As adubações foram realizadas em duas etapas, na semeadura $\left(1 / 3\right.$ das doses de $\left.\mathrm{N}_{\text {e }} \mathrm{K}_{2} \mathrm{O}\right)$ e, 30 dias depois, o restante, em cobertura. Para a semeadura utilizou-se a cv. Crimson Sweet, cujas sementes foram distribuídas em quatro por cova, a uma profundidade de $2,5 \mathrm{~cm}$, realizandose o desbaste em duas etapas. A primeira quando as plantas apresentaram 3 folhas definitivas, retirando-se as plântulas menos desenvolvidas, permanecendo na cova três plântulas. O segundo desbaste, efetuado 15 dias após o primeiro, deixando uma planta por cova. Este raleamento foi realizado com a intenção de eliminar os frutos mal desenvolvidos e defeituosos deixando-se 4 frutos por planta.

Foram realizadas capinas manuais regulares para o controle das ervas daninhas, e no período de frutificação os frutos foram protegidos com plástico para evitar o contato direto com o solo, tendo os demais tratos fitossanitários sido realizados de acordo com a recomendação para a cultura.

A colheita foi iniciada aos 70 dias após a semeadura e prolongou-se durante oito dias, sendo realizada manualmente.

Depois de colhidos, os frutos foram pesados e, então, determinou-se à produção de frutos por planta $(\mathrm{kg})$, a massa média dos frutos $(\mathrm{kg})$, o número de frutos por planta, o diâmetro dos frutos $(\mathrm{cm})$, os sólidos solúveis totais ( ${ }^{\circ}$ Brix) e a produtividade $\left(\mathrm{t} \mathrm{ha}^{-1}\right)$. Para a determinação dos teores de sólidos solúveis, as amostras foram retiradas da parte do "coração" dos frutos, maceradas e o suco separado do tecido fibroso por meio de crivo. Os sólidos solúveis totais foram determinados por refratometria, com refratômetro manual.

Os resultados foram submetidos à análise de variância, aplicando-se o teste de Tukey ao nível de 5\% de probabilidade, e estudos de regressão através do ajuste das equações em função das doses de nitrogênio e potássio utilizados, realizados pelo programa estatístico SISVAR (FERREIRA, 2011).

\section{RESULTADOS E DISCUSSÃO}

Verificaram-se efeitos significativos das doses de $\mathrm{N}$ isoladamente para as variáveis estudadas, com exceção do número de frutos por planta (NFP). As doses de K e a interação entre as dosagens $\mathrm{N}$ e $\mathrm{K}$ não afetaram as variáveis experimentais (Tabela 2). 
Tabela 2. Valores médios obtidos da análise de variância para massa de frutos (MF), diâmetro de frutos (DF), número de frutos por planta (NFP), sólidos solúveis totais (SST), produção por planta (PP) e produtividade (PROD), em função de doses de nitrogênio e potássio, sobre a cultura da melancia. Belém/PA, 2011.

\begin{tabular}{lcccccccc}
\hline \multicolumn{2}{c}{ Causas de Variação } & G.L. & MF & DF & NFP & SST & PP & PROD \\
\hline & N & 3 & $2,80^{*}$ & $2,10^{*}$ & $2,15^{\mathrm{NS}}$ & $3,27^{*}$ & $3,49^{* *}$ & $3,39^{* *}$ \\
Valor de F & $\mathrm{K}$ & 3 & $1,50^{\mathrm{NS}}$ & $2,05^{\mathrm{NS}}$ & $0,37^{\mathrm{NS}}$ & $2,24^{\mathrm{NS}}$ & $0,36^{\mathrm{NS}}$ & $0,69^{\mathrm{NS}}$ \\
& $\mathrm{N}$ x K & 9 & $1,00^{\mathrm{NS}}$ & $1,16^{\mathrm{NS}}$ & $1,68^{\mathrm{NS}}$ & $1,10^{\mathrm{NS}}$ & $1,02^{\mathrm{NS}}$ & $1,06^{\mathrm{NS}}$ \\
& & & 34,54 & 3,8 & 25,91 & 6,86 & 20,21 & 14,3 \\
C.V. $(\%)$ & & & 3,9 & 18,7 & 5,54 & 8,22 & 21,8 & 72,67 \\
Média & & &
\end{tabular}

A resposta não significativa à aplicação de potássio e sua interação com o nitrogênio pode ter sido ocasionada pela época de cultivo, que se caracteriza por baixa pluviosidade no período. A menor precipitação compreendida de agosto a novembro proporcionou pouca umidade do solo, provocando a redução da absorção de $\mathrm{K}^{+}$ pela diminuição da mobilidade deste nutriente, não ocasionando com a mesma intensidade a absorção de $\mathrm{N}$, haja vista, o processo de absorção de ambos, sendo o $\mathrm{K}^{+}$por difusão e $\mathrm{N}$ fluxo de massa. (MALAVOLTA, 1980; MARSCHNER, 1995). A baixa absorção de potássio pela planta limita a absorção de nitrogênio, mesmo esse em teores adequados para uma elevada produção (BÜLL, 1993).

As doses de $\mathrm{N}$ influenciaram significativamente a massa de frutos de melancia, ajustando-se ao modelo quadrático de regressão (Figura 2). A massa de fruto foi obtida com rendimento máximo de $4,65 \mathrm{~kg}$ com a dose de 99,5 kg de $\mathrm{N} \mathrm{ha}^{-1}$. Comparando os resultados encontrados por Cecílio Filho e Grangeiro (2004) e Araújo et al., (2011), verifica-se que os ganhos de massa média $(9,5 \mathrm{e}$ 7,0 kg) são superiores aos obtidos no experimento, porém, em doses maiores 248,5 e $120 \mathrm{~kg}$ de $\mathrm{N} \mathrm{ha}^{-1}$ respectivamente.

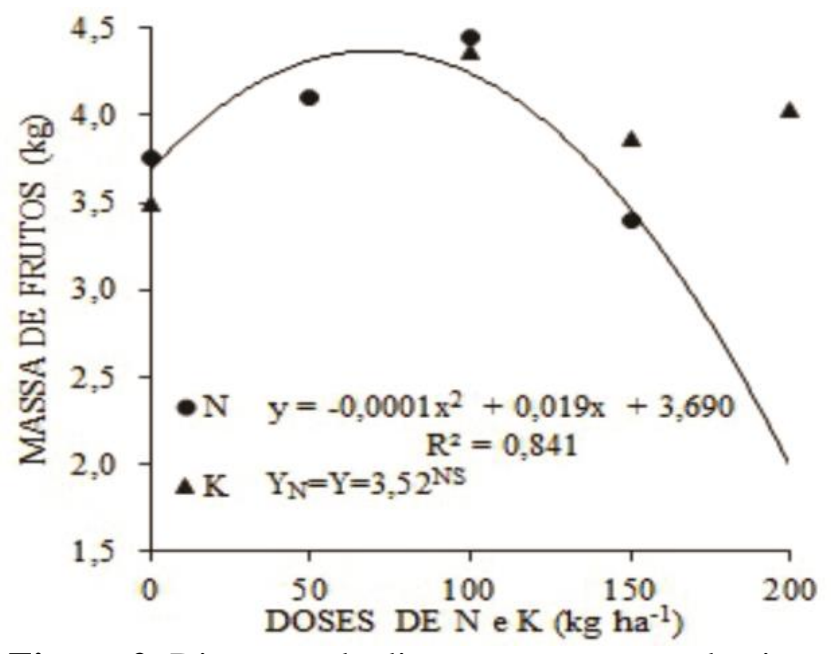

Figura 2. Diagrama de dispersão e equação de ajuste para massa de frutos da melancieira em função de doses de nitrogênio $(\mathrm{N})$ e potássio $(\mathrm{K})$. Belém/PA, 2011.

De acordo com Diniz Neto (2012), o modelo polinomial quadrático tem sido o que melhor representa a resposta das culturas à adubação nitrogenada. Este comportamento sugere que as dosagens estabelecidas nos tratamentos foram adequadas para o estudo, mostrando aumentos significativos na produção com as dosagens iniciais, atingindo um ponto máximo e decrescendo nas maiores dosagens.

A massa média de frutos foi de $3,90 \mathrm{~kg}$, considerada por Carvalho (2005) como frutos de porte pequeno $(<6 \mathrm{~kg})$. Esse fato pode ser 
explicado pelo déficit hídrico na fase inicial de desenvolvimento da planta e número de frutos por planta, que de acordo com Duarte et al., (2008), em excesso, afeta desfavoravelmente o peso dos frutos.

Os resultados obtidos com o diâmetro dos frutos se ajustaram ao modelo de regressão polinomial quadrática, sendo o valor máximo de $19,11 \mathrm{~cm}$, atingido na dosagem de $65,94 \mathrm{~kg}$ de $\mathrm{N}$ $\mathrm{ha}^{-1}$ (Figura 3). Diferindo dos resultados encontrados por Bardiviesso et al., (2013), em que a aplicação de diferentes doses de nitrogênio não promoveu diferenças significativas no diâmetro de frutos de melão amarelo "Frevo".

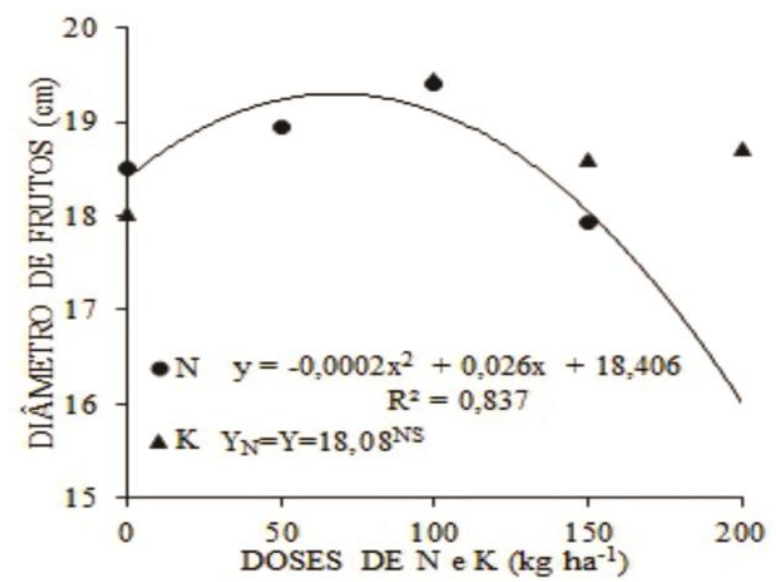

Figura 3. Diagrama de dispersão e equação de ajuste para o diâmetro de frutos da melancieira em função de doses de nitrogênio $(\mathrm{N})$ e potássio $(\mathrm{K})$. Belém/PA, 2011.

O comportamento do diâmetro do fruto acompanhou como esperado a massa de frutos, mostrando também acréscimo no crescimento até a dosagem de $100 \mathrm{~kg}$ de $\mathrm{N} \mathrm{ha}^{-1}$.

Araújo et al., (2011) observaram que o $\mathrm{N}$ foi o segundo elemento mais acumulado pela melancieira e o segundo elemento mais exportado pelos frutos, destacando a importância da correta adubação nitrogenada para o desenvolvimento e manutenção da capacidade produtiva do solo.

As dosagens de nitrogênio afetaram significativamente $(\mathrm{p}>0,05)$ a qualidade dos frutos no que se refere aos sólidos solúveis totais (SST). Observa-se que os valores de ${ }^{\circ}$ Brix se ajustaram ao modelo de regressão quadrática
(Figura 4) atingindo valores de 8,5 na dose máxima de $38,57 \mathrm{~kg} \mathrm{ha}^{-1}$.

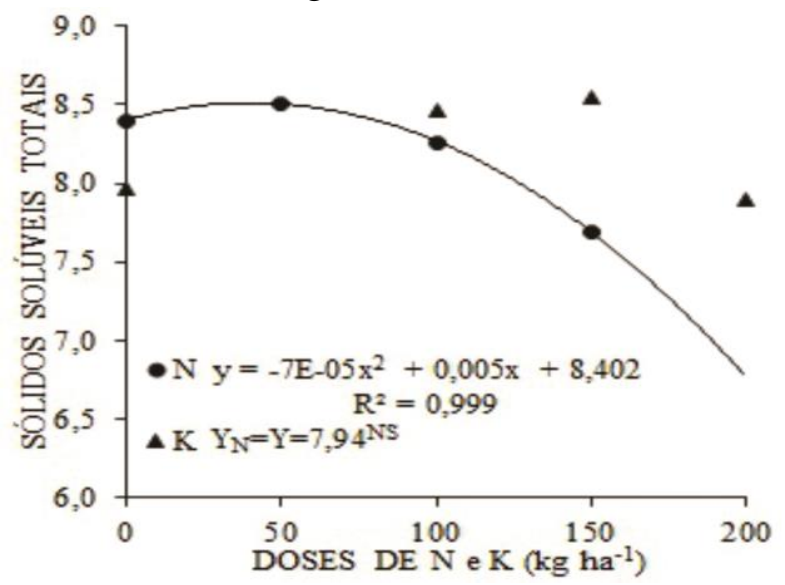

Figura 4. Diagrama de dispersão e equação de ajuste para sólidos solúveis totais ( ${ }^{\circ}$ Brix) da melancieira em função de doses de nitrogênio $(\mathrm{N})$ e potássio $(\mathrm{K})$. Belém/PA, 2011.

Morais et al., (2008) estudando o efeito do nitrogênio e lâminas de água, no Vale do Curu, Ceará, obtiveram respostas com o modelo quadrático cujos valores máximos de ${ }^{\circ}$ Brix foram de 10,27 obtidos com a aplicação de $198 \mathrm{~kg} \mathrm{ha}^{-1} \mathrm{de}$ nitrogênio e lâmina de água de $316 \mathrm{~mm}$.

Barros et al., (2012) em experimento no município de Boa Vista (Roraima), observaram que a aplicação de $\mathrm{N}$ influenciou os SST dos frutos de melancia, atingindo o máximo em $162,75 \mathrm{~kg}$ de $\mathrm{N} \mathrm{ha}^{-1}$, e reduzindo a medida em que se aumentaram os níveis de nitrogênio.

Observa-se que os resultados encontrados para os SST estão abaixo da faixa considerada ideal (entre 10 e $13 \%$ ) descrita por Bleinroth (1994). Esses resultados podem estar relacionados ao excessivo número de frutos por planta, que eleva a demanda de fotoassimilados, gerando forte competição entre os frutos e órgãos vegetativos, diminuindo os SST dos frutos (DUARTE et al., 2008).

A maior produção de frutos por planta foi obtida com a dosagem máxima de $61,03 \mathrm{~kg}$ de $\mathrm{N}$ $\mathrm{ha}^{-1}$ com peso médio de $25,97 \mathrm{~kg}$. A partir desta ocorreu redução na produção com um decréscimo de aproximadamente $60 \%$ até a última dose aplicada (Figura 5). Esses resultados diferem dos encontrados por Araújo et al., 
(2011), em que a média de frutos por planta diminuiu significativamente com o aumento de doses de nitrogênio, obtendo uma equação linear decrescente. Costa et al., (2013) não encontrou resultados significativos nos valores médios de número de frutos por planta com a aplicação de doses de $\mathrm{N}$ em melancieira cultivar Shadow.

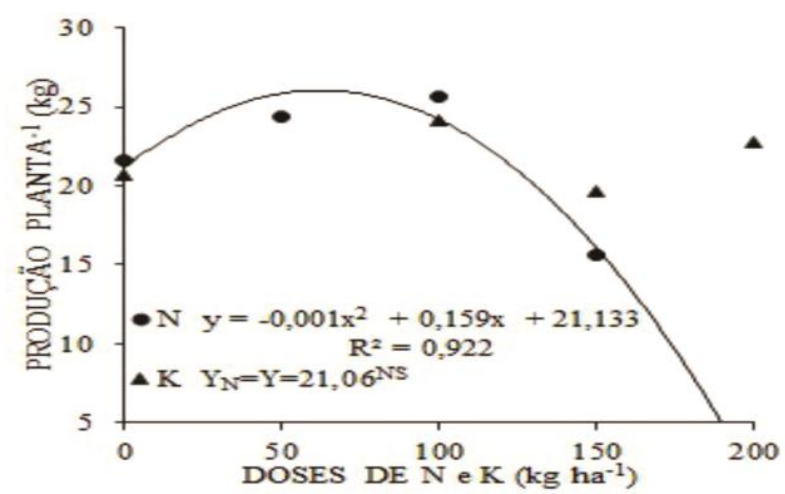

Figura 5. Diagrama de dispersão e equação de ajuste para produção por planta de frutos da melancieira em função de doses de nitrogênio $(\mathrm{N})$ e potássio $(\mathrm{K})$. Belém/PA, 2011.

O nitrogênio é importante para aperfeiçoar a produção das plantas (EHSANIPOUR et al., 2012), mas quando aplicado em grandes quantidades, a planta passa a assimilar apenas o necessário e o direciona principalmente para o desenvolvimento da parte vegetativa.

A produtividade $\left(\mathrm{t} \mathrm{ha} \mathrm{h}^{-1}\right)$ se ajustou ao modelo quadrático de regressão atingindo a máxima produção na dosagem de 66 de $\mathrm{N} \mathrm{kg} \mathrm{ha}^{-}$ 1 , com produtividade igual a $87,86 \mathrm{t} \mathrm{ha}^{-1} \mathrm{de}$ frutos (Figura 6).

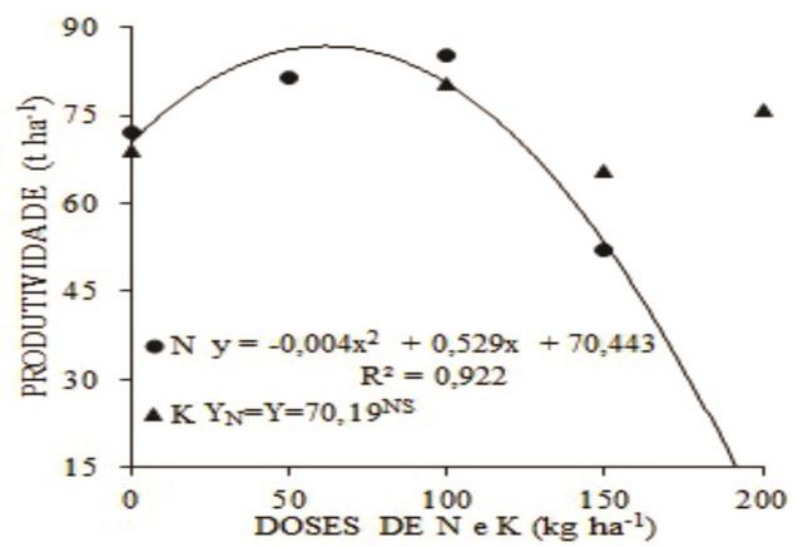

Figura 6. Diagrama de dispersão e equação de ajuste para produtividade de frutos da melancieira em função de doses de nitrogênio $(\mathrm{N})$ e potássio $(\mathrm{K})$. Belém/PA, 2011
Barros et al., (2012) trabalhando com adubação nitrogenada na cultura da melancia, obtiveram valor máximo de produtividade de 40,44 t ha ${ }^{-1}$ com 144,76 kg ha-1 de N. Oliveira et al., (2012) estudando a eficiência da água e potássio, encontraram produtividade máxima de $38,63 \mathrm{t} \mathrm{ha}^{-1}$, aplicando $150 \mathrm{~kg}$ de $\mathrm{N} \mathrm{ha}^{-1}$ e $60 \mathrm{t}$ de $\mathrm{K} \mathrm{ha}^{-1}$. Os valores de produtividade obtidos por esses autores são inferiores aos encontrados neste experimento, que pode ser atribuído ao efeito significativo do $\mathrm{N}$ aplicado.

Em pesquisa realizada por Garcia e Sousa (2002), verificou-se que as melhores produtividades comerciais de melancia foram obtidas com a aplicação de adubação nitrogenada variando de 40 a $120 \mathrm{~kg}$ de $\mathrm{N} \mathrm{ha}^{-1}$. Já Morais et al., (2008) obtiveram produtividade de 77,80 t $\mathrm{ha}^{-1}$, bem próximo ao do experimento, mas utilizando uma dose de $300 \mathrm{~kg}$ de $\mathrm{N} \mathrm{ha}^{-1}$. Estes resultados demonstram a importância da adequada adubação nitrogenada para o incremento produtivo da cultura da melancia.

\section{CONCLUSÕES}

As produções por planta e produtividade da melancia aumentaram com as aplicações das doses de nitrogênio até $100 \mathrm{~kg} \mathrm{ha}^{-1}$, reduzindo gradativamente até a dosagem mais alta.

As doses de 99,5 e 65,9 $\mathrm{kg} \mathrm{ha}^{-1}$ de nitrogênio proporcionaram maior massa $\mathrm{e}$ diâmetro de frutos, respectivamente.

A massa de fruto, diâmetro de frutos e os teores de sólidos solúveis totais encontrados foram baixos em relação às doses de $\mathrm{N}$ e $\mathrm{K}$ aplicadas.

As interações entre as doses potássicas e nitrogenadas não causaram efeitos que favoreceram efetivamente à melancia.

\section{REFERÊNCIAS}

ARAÚJO, W.F.; BARROS, M.B.; MEDEIROS, R.D.; CHAGAS, E.A.; NEVES, L.T.B.C. Crescimento e produção de melancia submetida 
a doses de Nitrogênio. Revista Caatinga, v. 24, n. 4, p. 80-85, 2011.

BARDIVIESSO, D.M.; MARUYAMA, W.I.; REIS, L.L.; SILVA, E.A.; BISCARO, G.A.; OLIVEIRA, A.C. Adubação nitrogenada na produtividade e qualidade de melão amarelo "Frevo" no município de Cassilândia-MS. Revista Agrarian, v. 6, n. 20, p. 140-147, 2013.

BARROS, M.M.; ARAÚJO, W.F.; NEVES, L.T.B.C.; CAMPOS, A.J.; TOSIN, J.M. Produção e qualidade da melancia submetida à adubação nitrogenada. Revista Brasileira de Engenharia Agrícola e Ambiental, v. 16, n. 10, p. 1078-1084, 2012.

BLEINROTH, E.W. Determinação do ponto de colheita. In: Netto, A.G. (ed.). Melão para exportação: Procedimentos de colheita e póscolheita. Brasília: MAARA/FRUPEX. p. 11-21, 1994.

BÜLL, L.T. Nutrição mineral do milho. In: BULL, L.T.; CANTARELLA, H. (ed) Cultura do milho: fatores que afetam a produtividade. Piracicaba: POFAFOS, 1993. p. 63-145.

CARVALHO, R.N. Cultivo de melancia para agricultura familiar. $2^{\mathrm{a}}$ edição, revista $\mathrm{e}$ ampliada. Brasília - DF: EMBRAPA Informação Tecnológica, 112p, 2005.

CECÍlIO FILHO, A.B.; GRANGEIRO, L.C. Produtividade da cultura da melancia em função de fontes e doses de potássio. Ciência e agrotecnologia, v. 28, n. 3, p. 561-569, 2004.

COSTA, A.R.F.C.; MEDEIROS, J.F.; PORTO FILHO, F.Q.; SILVA, J.S.; COSTA, F.G.B. \& FREITAS, D.C. Produção e qualidade de melancia cultivada com água de diferentes salinidades e doses de nitrogênio. Revista Brasileira de Engenharia Agrícola e Ambiental, v. 17, n. 9, p. 947-954, 2013.

CRAVO, M.S.; VIÉGAS, I.J.M.; BRASIL, E.C. Recomendações de adubação e calagem para o estado do Pará. $1^{a}$ ed. Belém, PA: Embrapa Amazônia Oriental, 262 p. 2007.
DINIZ NETO, M.A.; SILVA, I.F.; DINIZ, B.L.M.T.; PEREIRA, A.A.; PEREIRA, A.R. Componentes de Produção de Mamona em função de níveis de adubação nitrogenada e desfolha. Revista Ciência Agronômica, v. 43, n. 3, p. 546-553, 2012.

DONG, H.; LI, W.; ENEJI, A.E.; ZHANG, D. Nitrogen rate and plant density effects on yield and late-season leaf senescence of cotton raised on a saline field. Field Crops Research, n. 126, p. 137-144, 2012.

DORDAS, C.A.; SIOULAS, C. Safflower yield, chlorophyll content, photosynthesis, and water use efficiency response to nitrogen fertilization under rainfed conditions. Industrial Crops and Products, v. 27, n. 1, p. 75-85, 2008.

DUARTE, T. S.; PEIL, R. M. N.; BACCHIS, S.; STRASSBURGUER, A. S. Efeito da carga de frutos e concentrações salinas no crescimento do meloeiro cultivado em substrato. Horticultura Brasileira, v. 26, n. 3, p. 348-353, 2008.

EHSANIPOUR, A.; RAZMJOO, J.; ZEINALI, $\mathrm{H}$. Effect of nitrogen rates on yield and quality of fennel (Foeniculum vulgare Mill.) accessions. Industrial Crops and Products, v. 35, n. 1, p. 121-125, 2012.

EMBRAPA - Centro Nacional de Pesquisas de Solos. Sistema Brasileiro de Classificação de Solos. Rio de Janeiro: ( $2^{\mathrm{a}}$ Ed.) EMBRAPA Solos, 306p, 2006.

FELTRIM, A. L. Produtividade de melancia em função da adubação nitrogenada, potássica e população de plantas. 2010. 87f. Tese (Doutorado em Agronomia) - Universidade Estadual Paulista "Julio de Mesquita Filho", Jaboticabal.

FERREIRA, D. F. Sisvar: a computer statistic alanalysis system. Ciência e Agrotecnologia, v. 35, n. 6, p. 1039-1042, 2011.

GARCIA, L.F.; SOUSA, V.A.B. Influência do espaçamento e da adubação nitrogenada sobre a 
produção da melancia. Revista de la Facultad de Agronomia, v. 28, n. 1, p. 59-70, 2002.

HUANG, Y.; LI, J.; HUA, B.; LIU, Z., FAN, M.; BIE, Z. Grafting onto different rootstocks as a means to improve watermelon tolerance to low potassium stress. Scientia Horticulturae, v. 149, n. 4, p. 80-85, 2013.

KUMAR, P.; PANDEY, S.K.; SINGH, B.P.; SINGH, S.V.; KUMAR, D. Influence of source and time of potassium application on potato growth, yield, economics and crisp quality. Potato Research, v. 50, n. 1, p. 1-13, 2007.

LIU, C.F. Status and prediction in 2009 of the potassium fertilizer market in China. China Agricultural Technology Extension, n. 25, p. 33-36, 2012.

MALAVOLTA, E. Elementos de nutrição mineral de plantas. Piracicaba: Agronômica Ceres, 1980. 251p.

MARSCHNER, H. Mineral nutrition of higher plants. $2^{a}$ ed. San Diego: Academic Press, 1995. $862 \mathrm{p}$.

MORAIS, N.B.; BEZERRA, F.M.L.; MEDEIROS, J.F.; CHAVES, S.W.P. Resposta de plantas de melancia cultivadas sob diferentes níveis de água e de nitrogênio. Revista ciência agronômica, v. 39, n. 3, p. 369-377, 2008.

OLIVEIRA, P.G.F.; MOREIRA, O.C.; BRANCO, L. M. C.; COSTA, R. N. T.; DIAS, C.N. Eficiência de uso dos fatores de produção água e potássio na cultura da melancia irrigada com água de reuso. Revista Brasileira de
Engenharia Agrícola e Ambiental, v. 16, n. 2, p. 153-158, 2012.

RENGEL, Z.; DAMON, P.M. Crops and genotypes differ in efficiency of potassium uptake and use. Physiologia Plantarum, v. 133, n. 4, p. 624-636, 2008.

ROCHESTER, I.; O'HALLORAN, J.; MAAS, S.; SANDS, D.; BROTHERTON, E. Monitoring nitrogen use efficiency in your region. The Australian Cottongrower, n. 28, p. 24-27, 2007.

SILVA, J. S. Evapotranspiração e produção de melancia sob diferentes níveis de nitrogênio e da salinidade da água de irrigação. 2010. 98f. Dissertação (Mestrado em Irrigação e Drenagem) - Universidade Federal Rural do Semi - Árido, Mossoró.

TEODORO, R.E.F.; ALMEIDA, F.P.; LUIZ, J.M.; MELO, B. Diferentes lâminas de irrigação por gotejamento na cultura de melancia (Citrullus lanatus). In: CONGRESSO BRASILEIRO DE ENGENHARIA AGRÍCOLA, 31. Salvador. Anais... Salvador: Sociedade Brasileira de Engenharia Agrícola, UFBA, 2002.

WANG, X. H.; LIU, H.; ZHANG, Y.; HU, W. Effects of different potassium levels on yield and quality of watermelon. Xinjiang Agricultural Sciences, v. 47, n. 10, p. 2001-2004, 2010.

ZHANG, H.J.; DONG, H.Z.; LI, W.J.; ZHANG, D.M. Effects of soil salinity and plant density on yield and leaf senescence of field-grown cotton. Journal of Agronomy \& Crop Science, v. 198, n. 1, p. 27-37, 2012. 